\title{
Inovação na produção de polpa a partir de fibras curtas de eucalipto
}

\author{
Marina Rodriguez Brochado (CEFET/RJ) marina@cefet-rj.br \\ Luciana Marelli Mofati (CEFET/RJ) lucianamofati@aol.com \\ Cláudia Augusta Choeypant (CEFET/RJ) claudiach@click21.com.br \\ Marcelo Cardoso Pereira (CEFET/RJ) marcelo.cardoso@pop.com.br \\ Christian Nolte (CEFET/RJ) chnolte@e-xcellentia.com
}

\section{Resumo}

Este artigo tem como objetivo estudar as inovações introduzidas no setor de produção de polpa de celulose a partir de fibras curtas, contextualizando o setor no Brasil e no mundo. A metodologia utilizada abrange uma revisão bibliográfica e estudo de caso, mostrando que a conjunção de políticas governamentais, investimentos e postura empresarial adequada tornaram possível potencializar a demanda internacional em um setor dominado por fibras longas.

Palavras-chave: Inovações, polpa, fibras curtas, reestruturação produtiva.

\section{Introdução}

O mercado mundial de polpa ainda é dominado pela produção a partir de fibras longas. Contudo, desde a década de 70 , foram implementadas no Brasil várias inovações no desenvolvimento florestal de eucaliptos, que fizeram com que as fibras curtas ganhassem impulso no mercado mundial. Para entender melhor estas inovações e como elas foram decisivas na criação de demanda internacional, será feita uma análise do setor, utilizando uma metodologia que abrange uma revisão bibliográfica ilustrada por um estudo de caso de uma empresa representativa do setor.

Segundo Montaña (2001), "uma definição clássica diz que a inovação na indústria inclui o desenho, a produção e as ações de venda que formam parte do marketing de um produto novo e melhorado e também o primeiro uso comercial de um processo ou uma parte da equipe produzindo novo ou melhorado. A inovação na empresa consiste na utilização de novos conhecimentos para oferecer os produtos e serviços novos que desejam os consumidores".

Para Bateman e Snell (1998), inovação é algo que encontramos em um produto, processo ou procedimento melhor para realizar uma tarefa, ou ainda, uma mudança na tecnologia. E na visão de Loilier e Tellier (1999), inovação aparece como um conceito ao mesmo tempo polissêmico e polimorfo, pois a inovação está em toda parte, existindo numerosas classificações propostas, podendo ser de naturezas, produto, método ou processo; de origens, em nova técnica ou de marketing; ou de amplitudes, incrementais ou radicais. Segundo Loilier e Tellier (1999), existe uma relação entre a intensidade do risco e a natureza da inovação. A atividade inovadora provoca para a empresa riscos tecnológicos, técnicos e de marketing. Os riscos tecnológicos dizem respeito ao desenvolvimento da tecnologia; os técnicos à industrialização e à aplicação das tecnologias, e os de marketing referem-se à divulgação da tecnologia e à compreensão do ambiente.

Um outro fator relacionado ao êxito e fracasso das inovações corresponde à eficácia da comunicação. Segundo Nadler (1993), a necessidade de inovação competitiva exigiu que muitas empresas buscassem uma maneira de aumentar tanto o senso de responsabilidade como o grau de poder de ação das equipes, em todos os níveis, e isto só é possível através da 
combinação do grande potencial de tecnologia da informação com as grandes exigências do ambiente competitivo o que levou às Inovações no projeto organizacional.

Como resultado, o artigo mostra que a introdução destas inovações, com a conseqüente redução de custos, foi capaz de potencializar a demanda de polpa de celulose de fibras curtas em um ambiente dominado pela polpa de fibra longa. A fibra curta cresce mais rapidamente que a longa, fator determinante para que sua participação no mercado subisse de $23 \%$ em 1980 para $47 \%$ em 2003, com uma média de crescimento de $4,7 \%$ ao ano nos últimos 5 anos (ARACRUZ, 2004).

O custo reduzido também estimula uma demanda internacional de polpa de celulose de fibras curtas, reduzindo o uso de fibras longas, obtidas através de árvores com maior tempo de maturação. Por outro lado, a intensificação de tecnologias no processo produtivo gera um maior percentual de aproveitamento das toras, abrangendo-se outros usos, como para a construção civil e móveis ecológicos. A isto se soma a intensificação tecnológica no cultivo e desenvolvimento florestal, que levam a um maior aproveitamento de área produzida e em novas práticas de fomento, que repercutem socialmente ao nível local. Com a crescente competitividade dos custos das fibras curtas, a demanda mundial, oriunda sobretudo de países em desenvolvimento, passou de 10\% em 1984 para 33\% em 2003, tornando as perspectivas do setor bastante promissoras (ARACRUZ, 2004).

\section{A produção de polpa no mundo}

A história da produção de polpa para papel representa, por si só, o conceito de inovação, foco deste trabalho, pois demonstra a evolução da técnica em todos os processos históricos de disseminação de seu uso, que iniciam-se com a necessidade do registro escrito. Do homem primitivo à descoberta da escrita (apr. 6.000a.C.), registros da história do homem foram construídos como um arquivo cultural que transformou a sociedade. Primeiro como estilos rupestres, posteriormente como inscrições em peles de animais, evoluindo até a descoberta do papiro (Egito antigo, apr. 2.200 a.C.), quando é introduzido o conceito do uso da fibra, e consequentemente da polpa. E o princípio do uso da fibra prensada, combinada a outros materiais, como o algodão (no caso da civilização egípcia), é apropriado como conceito pelos chineses (751d.C), que difundiram o seu uso para o mundo.

Dessa forma, a evolução da produção de polpa para papel no mundo pode ser resumida, focando os aspectos de inovação no decorrer do tempo, a partir de sua difusão pelos árabes para o continente europeu (séc. VII), quando introduziram o amido derivado da farinha de trigo, para a colagem das fibras no papel e o uso de linho, cânhamo e outras fibras encontradas com facilidade, para a preparação da pasta, em substituição à cola animal, que reduziu o tempo de produção de 30 para 5 dias. Outro elo da cadeia de inovação é dado pelos holandeses (séc. XVII), quando introduzem os moinhos de martelo de papel movidos através da força eólica e posteriormente (séc. XVIII) pelo alemão Scheele, que descobre o efeito branqueador do cloro, aumentando a brancura do papel e viabilizando a entrada de trapos mais grossos e coloridos no processo, reduzindo o seu tempo de produção para cerca de 24 horas (HIPERTEXTO, 2004).

Outra inovação ocorre com o invento da máquina de folha contínua ou máquina de papel Fourdrinier (séc. XVII -XIX), que gera novos protótipos: a máquina cilíndrica e a máquina de partida automática. A partir deste início da automação do processo, as inovações significativas voltam-se para a incorporação de novos materiais, como a substituição da cola animal pela resina e alúmen e principalmente a pasta de fibras, criada por Frederich G. Keller (séc. XIX). Keller, ao utilizar madeira e trapos no processo de desfibramento, caracteriza a composição da pasta em fibras de celulose junto com outras substâncias, como a lignina. Esta 
descoberta introduz vários processos que separam as fibras de celulose da lignina, dos quais podemos destacar: processo de pasta mecânica, processo com soda, processo de sulfito e processo de sulfato. Isto permitiu a introdução de máquinas cada vez mais velozes: $1200 \mathrm{~m}$ por minuto (HIPERTEXTO, 2004).

Este quadro evolutivo ganha fôlego com a descoberta do uso da fibra de eucalipto para a obtenção da celulose e com a introdução da Máquina de Vertform que substitui a tela plana, sendo viabilizada pela descoberta de novas semipastas (ainda no séc. XIX). A partir daí, as inovações focam-se na produção florestal, através da difusão da biotecnologia, como uma garantia à produção em larga escala (séc. XX), e refletem-se na redução do tempo de cultivo e na padronização da forma das árvores (mais retilínias, o que evita perdas durante o processo). Os novos métodos de cultivo, agora padronizados, permitem uma redução do tempo de colheita e geram novas articulações empresariais no setor extrativo. Estas articulações via empresa, introduzem o Brasil no contexto internacional de produção de derivados de polpa de celulose de eucalipto, com a difusão do uso da fibra curta para a produção de papel.

\section{O eucalipto e o contexto nacional}

Antes de abordar o processo produtivo, é necessário entender a importância do eucalipto como matéria-prima na produção da polpa. Até a década de 70 , a celulose de pinho dominava o método de produção, enquanto a celulose de eucalipto era tida como uma fibra secundária. A celulose é um elemento estrutural da célula vegetal que existe em todos os gêneros e espécies florestais, mas o eucalipto apresenta o melhor desempenho conhecido para a produção industrial, não apenas pela característica de suas fibras, que garantem opacidade, maciez e alta absorção aos papéis, mas por produzir um alto volume de madeira por unidade de superfície em um curto ciclo de vida (em torno de seis a oito anos), o que permite grande rotatividade e aproveitamento do cultivo em escala. Também se adapta a ambientes desfavoráveis, como clima seco e solo de baixa fertilidade, e a ambientes diversos, possuindo centenas de espécies.

Essas características combinadas permitiram sua ampla utilização no setor de produção de polpa e direcionaram o plantio para a costa sudeste do Brasil, previamente exploradas durante o Ciclo do Café. Podemos citar como exemplo, a retirada da floresta nativa para a exploração do cultivo de café, produção de carvão e criação de gado no norte do Espírito Santo e no Sul da Bahia, que gerou graves problemas de exaustão do solo e de erosão. Neste exemplo, tais fatores, associados ao êxodo rural das áreas consideradas improdutivas e ao abandono das fazendas produtoras de café, pela queda do preço no mercado internacional, motivaram os investimentos em produção de eucalipto na região.

É necessário salientar que a ocupação dessas e de outras áreas contemplava uma estratégia de ampliação do parque industrial brasileiro, como uma medida de desconcentração do eixo RioSão Paulo, portanto, como parte desta estratégia, privilegiou-se a recuperação das regiões com um enfoque produtivo, através da disseminação do cultivo do Eucalipto. Assim, o Estado financiou o reflorestamento das áreas degradadas e fomentou parcerias com setores privados e com o BNDES, buscando a operacionalização das diretrizes dos planos.

Este plano de desenvolvimento integrado faz parte de uma política nacional de investimentos industriais, concebida pelo Plano de Metas. Ele tinha como base cinco áreas prioritárias para a destinação de investimentos (energia, transporte, alimentação, indústria básica e educação) e fixava metas a serem atingidas em cinco anos, sendo a indústria do papel e celulose um dos segmentos contemplados. No Plano, os dois objetivos para a o setor eram a "integração da produção de celulose à de papel e atingir a auto-suficiência na produção de celulose". Como conseqüência direta, o Banco Nacional de Desenvolvimento Econômico (BNDE - atual 
BNDES) é criado como banco de fomento, e possibilitou o primeiro grande investimento estatal no setor da indústria do papel e celulose em 1955 (LEITE, 1998).

Essas ações governamentais culminaram em uma Política de Incentivos Fiscais de 1966 (Lei 5106), que permitia a dedução de imposto de renda para investimentos em projetos de plantio, principalmente com eucalipto e pinus. Paralelamente, o BNDES garantiu empréstimos e fomentou políticas de desenvolvimento tecnológico na área de papel e celulose, além de pesquisas de mercado. A partir desta interação, foram fixados limites mínimos de produção de celulose (1968) para pedidos de empréstimos no setor. A posteriori, tem-se "a fixação pelo Conselho de Desenvolvimento Econômico (CDE), em 1972, de novos níveis mínimos de escala de produção, os quais foram adotados também pelo BNDES e resultaram no aumento expressivo da produção brasileira e no início das exportações". (JUVENAL \& MATTOS, 2002).

O II Plano Nacional de Desenvolvimento (II PND) (1974-1979) tinha como intenção criar uma opção de substituição de produtos em função da crise do petróleo e expansão das exportações de produtos manufaturados. Refletiu no setor, dando suporte a uma política de exportação. Neste contexto, o BNDES atualiza seu diagnóstico elaborado em 1966-67 para o setor de celulose e papel, gerando subsídios para o Primeiro Programa Nacional de Papel e Celulose (I PNPC), que confere o atual status do setor de papel e celulose. Além das metas e recomendações intrínsecas à produção, incentiva a pesquisa e o aprimoramento da tecnologia florestal (JUVENAL \& MATTOS, 2002).

A consolidação de um setor produtivo em um contexto nacional depende da compreensão prévia das relações existentes entre as economias externas e as vantagens comparativas nacionais, tanto ao nível da empresa quanto ao nível de localização espacial, isto devido às vantagens competitivas que a concentração de investimentos ao longo do tempo promovem à região de interesse, tal como observado na descrição dos planos acima (KRUGMAN, 1996).
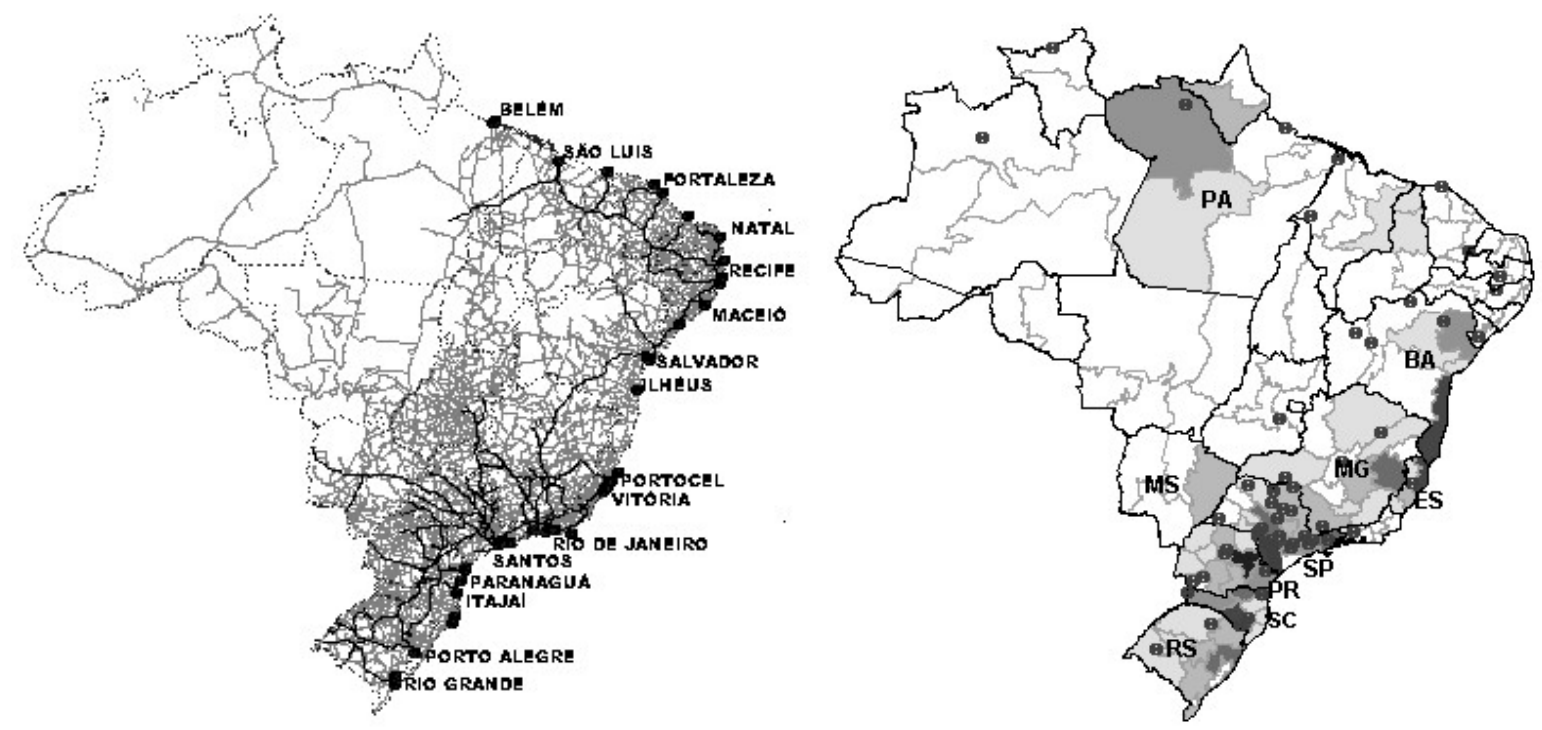

Mapas 1 e 2 - Mapas de Infra-estrutura em transportes (portos, rodovias e ferrovias) e de corredores regionais de produção de Eucalipto (1992 a 2002). Fonte dos dados: DNIT e SIDRA/IBGE 1990 a 2002.

Assim, as políticas de desenvolvimento do setor de polpa, valem-se de algumas 'vantagens' construídas para o setor de bens intermediários, ambientadas em um modelo de substituição de importações concebido no processo de intervenção planejada do Estado brasileiro. 
Tais políticas giram em torno de planos nacionais que consolidaram corredores produtivos localizados na região litorânea (como mostram os mapas abaixo), portanto, é necessário contextualizar a própria evolução industrial brasileira, que se pauta em um quadro evolutivo de investimentos em infra-estrutura direcionados para o escoamento de grãos e bens de capital, o que coloca a economia nacional no foco do capitalismo internacional, e por outro lado, consolida uma demanda crescente, que justificou mais investimentos concentrados regionalmente nos setores.

\section{O papel das inovações na produção de polpa}

As conceituações sobre as inovações tecnológicas analisadas enfatizam o caráter restruturador de seu uso no setor industrial e geram as inovações produtivas articuladas em uma nova arquitetura organizacional, que servem ao propósito deste estudo sobre o tema, qual seja, a inovação e suas implicações no setor produtivo.

Vale ressaltar que as aplicações das inovações científico-tecnológicas foram acentuadas pela introdução da microeletrônica, e que induziram a um conjunto de alterações na estrutura e na forma de se gerir as empresas, não mais consideradas fixas, mas agora articuladas em fluxos de informação, pessoas e mercadorias, que alteram significativamente a sua abrangência espacial e temporal, e intensificam a divisão técnica e social do trabalho. Deixam de ser empresas, e transformam-se em corporações através desta nova arquitetura organizacional em rede, gerando modelos de acumulação flexível e novas interfaces com outros segmentos produtivos e com outros setores da sociedade.

As inovações, neste sentido, transcendem o nível da empresa, passando a representar a própria ruptura de um modelo neoclássico de acumulação para este novo modelo de acumulação flexível, a exemplo dos trabalhos de Dreifuss (1996) e Gorender (1997), que descrevem a crise do modelo Fordista de produção baseado em economias de escala, evidenciando a sua inadequação frente às inovações tecnológicas, que dentre outras coisas, induziram a um conjunto de modificações e recondicionamento de sistemas, métodos e instrumentos de gestão e organização, provocando mudanças na localização (onde acontecem) e na atribuição (quem cumpre que função e que papel desempenha nesses processos), e alterando radicalmente a concepção, o tipo e a forma de utilização de insumos materiais, bem como a oferta de produtos, levando as empresas a buscarem novas formas de investimento baseada em aporte de ativos imateriais, incluindo know how de gestão e licenças de tecnologia, além de leasings, muitas vezes empregados nos serviços. Desta forma, a substituição das economias de escala por uma produção mais enxuta vem quase sempre acompanhada da adoção do modelo de trabalho e produção, cujos elementos fundamentais são a economia de escopo, as equipes de trabalho (células de produção) e o sistema just in time.

Estas alterações, no entanto, não podem ser encaradas como receitas genéricas, aplicáveis nos mais diferentes níveis de análise, como uma estratégia universal adotada por todas as empresas nos mais diversos setores. A reestruturação produtiva, nas palavras de Aquino (1998), deve englobar, também, decisões de caráter técnico-produtivo específicos a cada caso, traduzidos neste estudo do setor, e mais especificamente, na empresa analisada, em uma arquitetura organizacional enxuta, apoiando-se sobre terceirizados, ao mesmo tempo, permitindo um excelente fluxo de comunicações internas; portanto transcritas para diferentes formas de flexibilização da produção, gerando uma diversidade de estratégias de sistemas produtivos localizados. Assim, a expansão das atividades florestais da empresa em questão também se espelham nos diferentes contextos locais e regionais, o que para a autora, "permitem a alocação de investimentos com vistas à exploração dos recursos construídos (aquisições, fusões, seletividade espacial dos investimentos, etc)". E adicionamos que este impulso das atividades acarreta um clamor por novas regulamentações e ao mesmo tempo, 
encorajam outros investimentos paralelos que viabilizem, via desenvolvimento local, atingir a competitividade mundial (AQUINO, 1998).

Assim, o processo de reestruturação produtiva, via inovação tecnológica, confere um caráter mundial aos lugares, que se articulam às empresas, oferecendo também serviços fundamentais a sua reestruturação. Essas empresas, ao romper as barreiras do tempo e do espaço, passam a transcender as economias locais e ao atingir as economias externas ou a diversificação produtiva, transformam-se em corporações, tornando-se parte da estrutura hierárquica da arquitetura dos grupos que constituem o oligopólio mundial. Este último parágrafo reflete bem o exemplo analisado no estudo de caso escolhido.

Com relação ao processo de inovação no setor florestal de produção de eucalipto, como é o caso para qualquer outra inovação, as empresas que se destacam adotam estratégias que transcendem o uso da técnica, e pautam-se em uma gestão das operações bastante ágil e que permeia vários departamentos da empresa. Em empresas onde tantas inovações são implantadas em curto espaço de tempo, a arquitetura organizacional é fator importante. Segundo Nadler et al. (1993), os arquitetos devem "pensar em como a arquitetura permitirá à organização executas suas várias estratégias e realizar o trabalho exigido (perspectiva de desempenho estratégico/tarefa)", (...) "e devem considerar como a arquitetura se harmonizará com os indivíduos que trabalham para a organização, ou sobre eles terá um impacto (perspectiva sócio cultural)". Os autores também indicam que as empresas devem possuir adaptabilidade, flexibilidade, sensibilidade, decisão e rapidez para que possam responder de forma satisfatória às pressões. $\mathrm{O}$ histórico do setor em termos de inovações, crescimento, resultados financeiros e perspectivas mostram que a indústria nacional preenche estes requisitos (NADLER et al, 1993).

A produção de polpa no cenário nacional representa bem o impulso que uma política governamental pode ter na geração de inovações aplicadas a um setor. Na década de setenta, quando se inicia o cultivo em escala, a iniciativa privada já havia introduzido a tecnologia de seleção de sementes. Os impactos da introdução desta tecnologia geraram um aumento de produtividade da área de floresta (de 25 para 35 metros cúbicos de madeira por hectare/ano, no caso da empresa estudada). Este fato foi o grande encorajador dos investimentos em pesquisa florestal e mostraram que havia um espaço para a criação de demanda internacional de fibra curta, suportado pelos baixos custos no país (ARACRUZ, 2002).

Inicia-se, pois, a fase de pesquisas florestais que culminará com a introdução de uma inovação de peso, a saber, o método de propagação vegetativa baseado em técnicas de clonagem. Esta inovação permitiu o cultivo de árvores com qualidade de madeira uniforme, o que facilita o seu manuseio como insumo produtivo, além de gerar variedades mais resistentes a doenças e com um menor ciclo de crescimento. Como resultado, foi possível aumentar o rendimento e produzir em parcelas estruturadas em blocos, o que facilitou o transporte na colheita. Outro benefício do cultivo das parcelas de diferentes variedades se deu na redução da dispersão de pragas, e com este objetivo, em algumas empresas e de modo pioneiro no caso estudado, também foi mantida uma mata ciliar no entorno das parcelas, o que permitiu não somente o controle da dispersão, como aumentou o rendimento do solo. Este aumento de produtividade pode encorajar as empresas, que assim o desejarem, a destinar terras para áreas de preservação permanente, que podem ser cobertas em sua maioria pelas florestas nativas remanescentes, efetuando assim uma ação de preservação ambiental, que sempre encontra boa repercussão social.

\section{Estudo de caso de empresa nacional: diagnóstico da inovação tecnológica na produção de polpa de fibras curtas}


No caso da empresa escolhida para o estudo de caso, seu repertório de inovações significativas já se estende por mais de três décadas, sendo o resultado disso, a colocação da fibra curta no mercado mundial, fazendo com que esta conquistasse cada vez mais marketshare. Estas inovações só puderam ser implementadas, pois, as pressões de mercado, aliadas a uma Arquitetura Organizacional adequada e a um Planejamento Estratégico voltado para a monitoração de melhores práticas e sua posterior implementação, quando conveniente.

Dentre estas inovações, podemos citar as pesquisas com sementes selecionadas (entre 1968 e 1972), que aumentaram o rendimento de madeira/hectare/ano e a introdução do método de propagação vegetativa baseado em técnicas de clonagem (em 1979). Conseguiu-se também a redução do tempo de maturação da planta para 6 a 8 anos (entre 1967 e 1979), quando a média anterior era de 15 anos; a maior adaptabilidade ao ambiente local, reduzindo o $\mathrm{n}^{\mathrm{o}}$ de pragas; a desrama de galhos ( 2 a 4 anos), tornando a árvore reta e lisa, o que favorece o transporte das toras e o seu processamento posterior e o cultivo em parcelas, otimizando a logística de transporte das toras fora da estrada e o controle efetivo das parcelas por monitoramento via satélite. Também facilita o controle natural de pragas, reforçado pela manutenção de uma mata ciliar entre as principais cepas (ARACRUZ, 2002).

Mais próximo aos dias atuais, obteve-se a redução do consumo específico de madeira, com o processo de inovação da indústria (novo maquinário e tecnologias modernas na linha de produção, entre 1997 e 1999), gerando um aproveitamento maior por $\mathrm{m}^{3}$ e também uma conquista em termos logísticos, pois a expansão da área de floresta exigiu um intensivo transporte das toras, gerando duas otimizações: a intermodalidade no transporte, com investimentos intensivos em cabotagem e a terceirização do cultivo das parcelas (arrendatários) via fomento florestal, com a parceria da empresa e suas terceirizadas no corte e no deslocamento. No caso do fomento florestal, além do objetivo social, a empresa foi capaz de diminuir as distâncias médias entre as áreas cultivadas e as fábricas, o que também reduziu os custos de transporte e intensificou os investimentos em armazenamento (ver mapa 3).

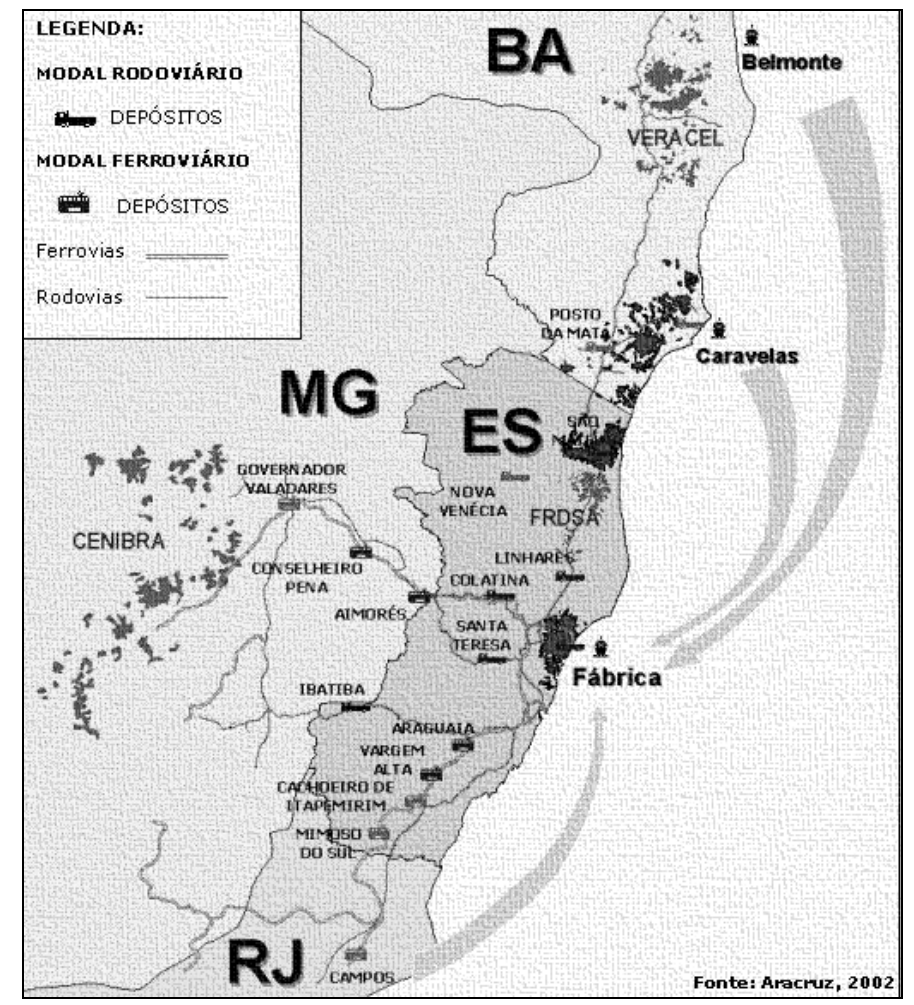

Mapa 3 - Mapa logístico de expansão das áreas de cultivo da empresa estudada. 


\section{Conclusão}

Este artigo, através de um panorama bibliográfico e do estudo de caso de uma empresa representativa do setor, mostra que a conjunção de políticas públicas conjugadas a investimentos e a uma postura empresarial direcionada a inovações, tornou possíveis o incremento da competitividade da polpa de celulose a partir de fibras curtas, em termos de custos, criando uma demanda internacional crescente. Esta demanda, além de crescente, torna-se cativa, visto que o setor apresenta contratos de longo prazo, com boas perspectivas de que esta aceitação aumente ainda mais. Além disso, estas inovações transcendem o escopo do uso industrial da polpa, infiltrando-se para as áreas de logística, meio-ambiente e social.

\section{Referências}

AQUINO, Gisela de (1998). Estrutura Organizacional e reestruturação produtiva. In: Revista Território. Ano III, $\mathrm{n}^{\mathrm{O}} 5$, jul/dez.

ARACRUZ (janeiro, 2004) - Apresentação APIMEC. Hipertexto disponível no site: www.aracruz.com.br. Acessado em: 29/04/2004.

ARACRUZ (março, 2002) - Relatório de Operação Florestal. Aracruz e IPSC. Material em CD.

BATEMAN, T.S., SNELL, S.A. (1998). Administração: construindo vantagem competitiva . São Paulo, Atlas.

CODESA (2000) - Plano de Desenvolvimento de Zoneamento dos Portos do Espírito Santo. Consulport. Espírito Santo.

DNIT/MT (2003). Banco de dados agregados (material para mapa gerado em Transcad 3.5). Disponível no site: http://www.dnit.gov.br.

DREIFUSS, René Armand (1996). A Época das Perplexidades: Mundialização, Globalização e Planetarização: novos desafios. Petrópolis, RJ. Vozes.

GORENDER, Jacob (1997). Globalização, Tecnologia e Relações de Trabalho. In: USP - Instituto de Estudos Avançados. 11 (29), janeiro/abril.

MONTAÑA, Jordi (2001). Innovación: El reto empresarial del siglo XXI. In: GÜELL, A. M.;VILA, M.(coord). El arte de innovar en la empresa. Barcelona, Ediciones del Bronce.

HIPERTEXTO (2004). Disponível no site: www.comofazerpapel.com.br/papelbrasil.htm. Acessado em 28/04/2004

JUVENAL, T. L., MATTOS, R. L. G. (dezembro, 2002). O setor de celulose e papel. In: BNDES. BNDES 50 anos: Histórias Setoriais.

KRUGMAN, Paul (1996). Development, Geography and Economic Theory (2 ed). Cambridge: MIT Press.

LEITE, A.L.S (1998). Concentração e desempenho competitivo no complexo industrial de papel e celulose 1987 a 1996. Dissertação de mestrado. Universidade Federal de Santa Catarina - UFSC. Florianópolis.

LOILIER, T., TELLIER, (1999). A Gestion de l'innovation - Décider - Mettre en oeuvre - Diffuser; Les Essentiels de la Gestion. Éditions Management Société, Paris.

NADLER,D.A.,GERSTEIN,M.S.,SHAW,R.B. (1993). Arquitetura Organizacional - A Chave para a Mudança Empresarial, São Paulo, Campus, $3^{\mathrm{a}}$. ed.

PORTOBRÁS. Resolução No 050/85 de 12 de março de 1985.

SIDRA/IBGE (1992 a 2002). Banco de dados Agregados (Material para mapa gerado em Transcad 3.5). Disponível no site: http://www.sidra.ibge.gov.br/bda/splash.htm. 